\title{
Investigating the Patterns and Prevalence of UK Trade Unionism on Twitter
}

\author{
Wil Chivers \\ WISERD, Cardiff University \\ 38 Park Place \\ Cardiff CF10 3BB \\ +442920875846 \\ ChiversWG1@cardiff.ac.uk
}

\author{
Helen Blakely \\ WISERD, Cardiff University \\ 38 Park Place \\ Cardiff CF10 3BB \\ +44292068 8726 \\ BlakelyH1@cardiff.ac.uk
}

\author{
Steve Davies \\ SOCSI, Cardiff University \\ King Edward VII Avenue \\ Cardiff CF10 3WT \\ +442920874435 \\ DaviesS27@cardiff.ac.uk
}

\begin{abstract}
This paper reports on on-going exploratory research into the prevalence and patterns of social media use by trade unions in the United Kingdom. Social media platforms, like Twitter, are used by unions to organize and mobilize existing and potential members by communicating relevant content, which often engages politicians and the news media. However, there is little empirical research examining how trade unions use social media in practice. This research addresses this gap by employing digital methods to analyze trade union activity on Twitter, namely, exploring key characteristics of Twitter use by UK unions and mapping dynamic networks of associations around labour movement issues. Findings are discussed in the context of collective and connective action. The methodological implications for studying civil society organizations online are also considered.
\end{abstract}

\section{CCS Concepts}

- Networks $\rightarrow$ Social media networks $•$ Networks $\rightarrow$ Online social networks • Applied Computing $\rightarrow$ Sociology

\section{Keywords}

Collective Action; Connective Action; Labour Movement; Social Media; Social Network Analysis; Trade Unions; Twitter

\section{INTRODUCTION}

A growing number of studies highlight the role of social media in promoting novel forms of organization in the "online", "digital" or "networked" public sphere [2, 6, 7, 20, 24, 27, 29]. These emergent forms of social organization have the power to transcend geographic and temporal constraints, connecting dispersed individuals and groups. In 2010, a Carnegie Trust report [8] investigated the potential impacts on civil society organizations of this fragmenting media landscape and the proliferation of social technologies. It identified both the potential of social technologies for these groups (large numbers of users, flexibility and accessibility) but also their pitfalls, such as competition for audience attention and the risk of using them ineffectively. Thus "success" with social media for civil society organizations is Permission to make digital or hard copies of part or all of this work for personal or classroom use is granted without fee provided that copies are not made or distributed for profit or commercial advantage and that copies bear this notice and the full citation on the first page. Copyrights for third-party components of this work must be honored. For all other uses, contact the Owner/Author.

\#SMSociety'17, July 28-30, 2017, Toronto, ON, Canada (C) 2017 Copyright is held by the owner/author(s).

ACM ISBN 978-1-4503-4847-8/17/07.

http://dx.doi.org/10.1145/3097286.3097315

This work is licensed under a

Creative Commons Attribution International 4.0 License predicated not only on its uptake, but also on the way in which they are used. However, there are clear parallels between the communicative aspects of social media and the potential for resource mobilization among both established and ad hoc social movements - the Occupy Wall Street movement a prominent example [12]. The questions guiding research in this area are how and why people think social media is used by civil society organizations and what benefits people think they have. How they are used in practice, and the networking effects generated are, by comparison, under-researched issues.

In the context of trade unionism and the labour movement, existing literature is largely oriented around attitudes towards information and communication technologies (ICTs) and factors affecting their uptake. For instance, evidence suggests union members have strong beliefs about the benefits of ICTs [26], use them more intensely than non-unionists [21] and are more willing to use social media outside of regular working hours [22]. Panagiotopolous and Barnett [23] also indicate the drive for modernization and pressure from members as key factors affecting social media uptake. As this paper illustrates, trade unions do have a visible presence on Twitter, although uptake of social media in general is still far from uniform across a range of global trade union organizations; a LabourStart survey in 2013 [18] identified that $63 \%$ of English speaking respondents reported that their union had a presence in social media networks. Within this, 92\% identified a Facebook presence while only $52 \%$ a Twitter presence.

Although response to, and uptake of social media amongst trade unions has been described as cautious [16] discussion in the literature frequently concerns the potential of these tools for revitalizing the labour movement [4, 17], whether through recruiting new members [10], reaching traditionally marginalized audiences [13], enhancing union power [19] or developing distributed discourses and transparency in union democracy [5, 14]. Absent from such analyses, however, are empirically-based, realtime or historical observations about how trade unions use social media (in this case, Twitter). A key point we take from existing research, nevertheless, is the dynamic, inclusive and multidimensional nature of social media. The actions of the trade union community online are not restricted to the organizational presence of the unions themselves. Where the potential of social technologies begins to assert itself in this context is in the capacity for a broader range of individuals, either employed by the unions and tweeting in a quasi-personal/professional capacity or connected to them informally, to engage with and promote trade union issues on Twitter. It is important to comprehend, then, on the one hand, how Twitter is used by unions and on the other, the character of the broader network of individuals and groups connected to trade unions. Our analysis of social media is concerned with mapping 
patterns, practices, networks, and connections. Consequently, this research seeks to uncover the specifics of how social media are being used in practice by trade unions and the dynamic social networks that are produced around the community as a result.

\section{OVERVIEW AND OBJECTIVES}

This Work-in-Progress paper reports on research into the prevalence and patterns of social media use by trade unions in the United Kingdom. The research has focused on Twitter, not least because Twitter data are easily accessible for researchers and conversations amenable to social network analysis. Given the relative lack of empirical research into Twitter use by unions in the UK (see Hodder and Houghton's [15] contribution) the research has two primary objectives. First, it aims to outline the extent to which trade unions affiliated to the UK Trades Union Congress (TUC) are present on Twitter (measured by indicators such as, at the most basic, whether they have an active Twitter account, followed by their volume of tweeting, follower base and those they choose to follow (which may or may not be a signal of endorsement), 'liked' tweets and the patterns in hashtag use).

Second, the research aims to build on this foundation and identify through social network analysis key individuals and organizations associated with online trade unionism in the UK. This is achieved in two ways. First, through the identification of patterns of conversation on Twitter around particular debates such as the '\#TUBill' (the Trade Union Bill debate in 2015/16). Second, by a process of snowball sampling - i.e., analyzing the tweets of a set of accounts and identifying further users who appear to engage more or less systematically with the extended trade union network.

The outcome will be an empirically grounded set of observations about the nature of UK trade unionism as it occurs on Twitter. Given that Twitter is a rapidly evolving, dynamic space any such observations are snapshots of a particular time, albeit a period of months. It will be necessary to continually update our knowledge of how these organizations and individuals interact on social media as well as they how they respond to current events as they unfold.

\section{METHODOLOGY}

\subsection{Sample}

The first stage of data collection identified a core group of relevant Twitter accounts for trade unions in the UK. Five of the UK's largest trade unions (based on membership) were selected: Unite, UNISON, PCS, Usdaw and GMB. The Twitter account for the TUC was also incorporated into the sample. As our research has progressed, it appears both feasible and logical to broaden the sample of trade unions to any of those present on Twitter (currently 42 of the 50 TUC-affiliated unions in the UK).

\subsection{Software and Tools}

Collection and analysis of Twitter data relating to these accounts was carried out using NodeXL Pro (v.1.0.1.383) [25] and Twitonomy [11]. NodeXL Pro was used to import user information and the latest 3,200 tweets from each identified account. It allows for social network analysis of Twitter conversations and users' networks. When analyzing the conversation around a hashtag, for example, clustering algorithms in NodeXL can help to identify the structure of communities that are typically formed by retweeting. While these patterns only provide a static snapshot of the network [3] this technique allows us to identify influential Twitter users at a particular moment. The same analysis conducted over a period of days, weeks or months will reveal the dynamics of the network over time. This method of analysis is helpful in observing the appearance and disappearance of certain users in response to offline events or news items.

Twitonomy, an online tool, was used for analyzing Twitter accounts, including recent and popular tweets, the potential reach of retweets and changes in friends and followers over time. While more useful for descriptive analysis, Twitonomy does provide insights quickly. The percentage or average number of tweets favourited or retweeted by others, for instance, is a helpful indicator of the importance other Twitter users attach to the tweets published by that account.

\subsection{Data Collection}

NodeXL was used to collect users' recent tweets on a rolling basis in order to collect every tweet over a period of six months. Owing to differences in volume of tweeting across the accounts we identified, the dates covered by our data collection strategy varied from the last couple of months to the last few years (where the 3,200 tweet limit had not been reached but the user had opened their account several years previous). The earliest tweet collected dated back to $3^{\text {rd }}$ February 2011 . For the most prolific tweeters, when data were collected in October 2016, the earliest tweets that could be obtained dated to June 2016. NodeXL was also used in late 2015 through to early 2016 to collect data concerned with the Trade Union Bill; the search criterion for these tweets being any containing the hashtag '\#TUBill'. These were collected at intervals, up to the permitted maximum of 18,000 tweets per search.

Twitonomy was first used for data collection January 2017, to complement previous collections of users' tweets from October 2016. An update to Twitter's API in November 2016 was of great practical value as it increased the maximum number of tweets that can be downloaded from a single user to 3,200 (from 200) and extended the time frame within which tweets can be re-collected. It also meant that descriptive analysis using Twitonomy was enhanced as the analytics provided by the platform were based on a much greater volume of tweeting.

\subsection{Ethical Considerations}

Ethical considerations for Twitter research typically centre on publishing the content of tweets and the issue of informed consent. Twitter's Best Practice for Media (static uses and publication) stipulates that if tweets are quoted, they should be accompanied by all user information associated with the tweet, including username and timestamp. Consequently, anonymization of tweets is not possible. For this research we are only interested in usage statistics and aggregated data and may only at a later date need to supplement this analysis with tweet content. In this case, we would seek approval from the School Research Ethics and follow Williams et al.'s [30] guidance that if tweets originate from a public figure or institutional account, who may reasonably expect their tweets to be public, consent to publish need not be sought.

\section{PRELIMINARY ANALYSIS}

The following highlights key findings from the preliminary stages of analysis of data and draws out questions for further analysis.

\subsection{Prevalence and Patterns of Twitter Use}

Table 1 illustrates some of the "vital statistics" for the initially identified trade union accounts. Unite, the largest trade union in the $\mathrm{UK}$, is also the most prolific tweeter. This is despite UNISON being the union with the longest history on Twitter, having joined in June 2008, eight months prior to Unite. By contrast, the larger follower base is perhaps to be expected given Unite's larger member base. Meanwhile, UNISON, followed by Usdaw, have significantly 
higher numbers of 'liked' tweets than the other unions (tweets they have liked, and not tweets of theirs liked by others). This practice adds another dimension to consider; what does liking signify? Liking makes tweets more accessible to followers and hence we may expect their content to be of special relevance to that union or their campaign agenda.

\begin{tabular}{ccccc}
\hline Org. & Tweets & Followers & Followed & Likes \\
\hline The TUC & 7,688 & 18,032 & 1,220 & 106 \\
Unite & 32,834 & 52,778 & 938 & 670 \\
UNISON & 27,644 & 42,583 & 2,515 & 1,763 \\
PCS & 19,675 & 23,901 & 990 & 169 \\
Usdaw & 7,349 & 5,746 & 340 & 1,277 \\
GMB & 2,990 & 16,225 & 666 & 636 \\
\hline \hline
\end{tabular}

Table 1. Key figures for trade union Twitter accounts

One disparity of interest is the number of people UNISON follow in comparison to the other trade unions. Twitonomy suggests that a greater ratio of followers to followed indicates stronger influence on Twitter. Seen in Table 2, Unite has a ratio of 57, in contrast to UNISON's of 17. Again, this may be a simple by-product of Unite's member base but it would also be worth considering whether it is a deliberate strategy for UNISON to follow a much greater number of people than other unions. Table 2 also illustrates that Unite's tweets are retweeted and liked far more frequently than those of the other unions, despite tweeting slightly less often than UNISON.

\begin{tabular}{ccccc}
\hline Org. & Ratio & Tweets/day & Retweet \% & Liked \% \\
\hline The TUC & 15 & 9.67 & 88.03 & 83.13 \\
Unite & 57 & 20 & 94.69 & 87.91 \\
UNISON & 17 & 21.87 & 20.2 & 19.2 \\
PCS & 25 & 7.48 & 74.7 & 65.21 \\
Usdaw & 17 & 9.22 & 49.1 & 48.6 \\
GMB & 23 & 1.62 & 33.99 & 28.27 \\
\hline \hline
\end{tabular}

Table 2. Usage statistics for trade union accounts

Finally, turning to the patterns of Twitter use drawn from Twitonomy, Figures 1 and 2 highlight the most frequently used hashtags by Unite and UNISON in their most recent 3,200 tweets respectively. Two observations arise from these charts. First, Unite appears to use hashtags with greater frequency than UNISON, which suggests they are attempting more often to generate or contribute to an emerging conversation on Twitter. Second is the difference in hashtags used. Unite's hashtags in Figure 1 suggest a broad-brush approach that touches on a variety of campaigns and issues, including Brexit, 'Save Our Steel' and 'No More Austerity'. UNISON's most used hashtag '\#undc16' was designed to promote their own conference in 2016. The second most popular hashtag '\#thankyourchampions' was the product of a UNISON campaign to thank those working in public services. These early findings suggest that content posted by trade unions on Twitter during the period of data collection was organized using hashtags that related to issues specific to that union.

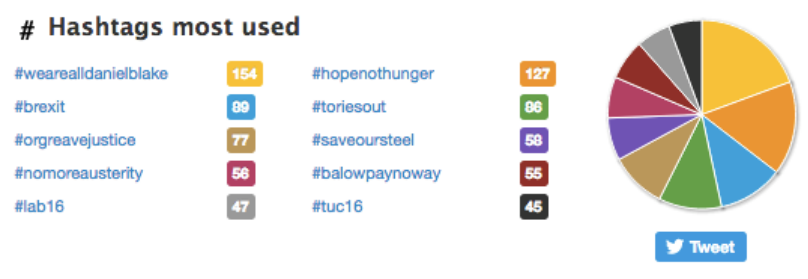

Figure 1. Most used hashtags by Unite (last 3,200 tweets)
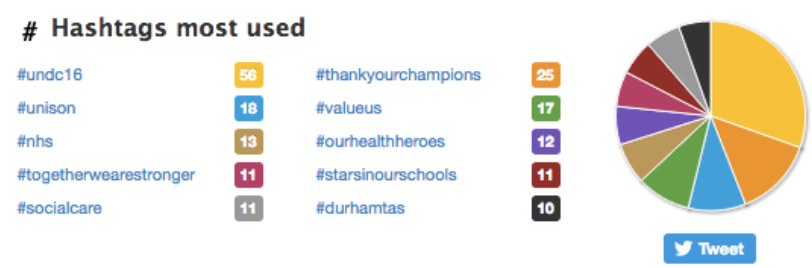

Figure 2. Most used hashtags by UNISON (last 3,200 tweets)

\subsection{Influence and Network Analysis}

Using NodeXL, we can also observe the effects of a hashtag being used by trade unions collectively to challenge legislative reform that would have a detrimental impact on the community. Figure 3 visualizes the network generated through the use of the '\#TUBill' hashtag in January 2016. Using NodeXL's built-in functionality the data were analyzed using a community detection algorithm [9], which created the visible clusters. The edges were colour coded to indicate the types of connections made, which in this instance were most frequently retweets. Consequently, the users at the centre of the clusters are those retweeted; any links between clusters indicate who else was mentioned in tweets by users in that group.

Identifying those at the centre of clusters builds up our image of who was influential on that date in promoting the Twitter conversation about the Trade Union Bill. The TUC, Unite and the CWU all generate their own clusters, while other organizations and individuals also had an impact: the General Secretary of the TUC Frances O'Grady (@francesogrady); the Scottish TUC (@ scottishtuc); the General Secretary of the CWUnion Dave Ward, and; the Twitter account for the Labour team in the House of Lords (@labourlordsuk).

In the lower left corner of Figure 3 is a collection of smaller clusters. These are all Welsh-based Twitter accounts including Welsh Labour (@welshlabour), the Welsh Government (@welshgovernment), Plaid Cymru (@plaid_cymru), Jo Stevens MP (@jostevenslabour) and Leighton Andrews AM (@leightonandrews). The reason for this pattern is that on the $28^{\text {th }}$ January 2016 the Welsh Assembly voted against the proposals of the Trade Union Bill. This event was reported on social and news media and consequently the impact on the network was to create a 


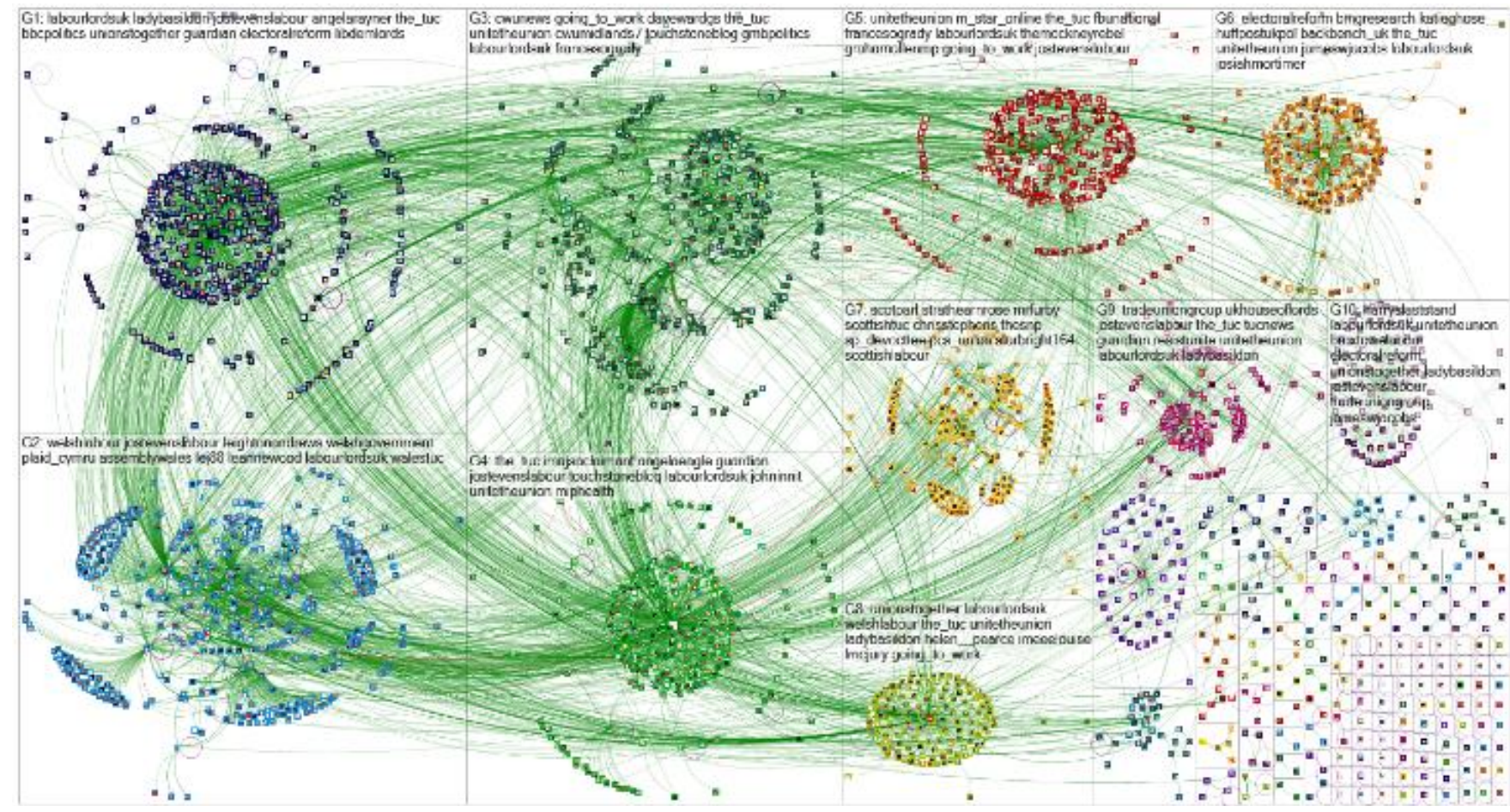

Figure 1. \#TUBill NodeXL network (28th January 2016): Clusters formed around key users by retweeting patterns

transitory sphere of influence around these Welsh actors. These dynamic qualities of the network aid our understanding both of how different actors engage with trade unions over time, and how trade union Twitter activity can be responsive to offline events. As intimated above, these findings highlight the need to consider the interactions not only between trade unions and their followers but also between an extended network of public and third sector organizations and individuals working around issues pertinent to trade unionism.

\section{CONCLUSIONS AND CONTRIBUTIONS}

This research has yielded useful insights into the prevalence and patterns of Twitter usage among trade unions and their extended networks in the UK. Ultimately, we will be in a position to characterize patterns of Twitter use among the core trade unions as well as the broader network of individuals and organizations that interact dynamically [28] and to differing degrees on the periphery of this community. Unite, the biggest trade union, does appear so far to be one of the most engaging and potentially influential unions on Twitter. As the research progresses, it will be interesting to attempt to qualify Panagiotopolous and Barnett's [23] suggestion that union size may be a predictor of online communication strategy/preference by observing the patterns of smaller unions alongside those with significantly larger member bases.

Evidently, UK trade unions are far from a silent voice on Twitter. The passage through parliament of the Trade Union Bill generated significant debate both offline and on Twitter, where the hashtag '\#TUBill' was used to collectively voice dissent against the Bill. While this was ultimately passed into law, these debates were disseminated widely on Twitter, driven by a core group of trade unions, the TUC, official representatives of these groups and politicians. Theoretically, however, this raises a number of questions about the impact of social media on trade unions. Specifically, trade unions still appear to be the driving force behind relevant debates on Twitter (through being retweeted widely).
Despite these debates being digitally-mediated, this stands in contrast to Bennett and Segerberg's notion of "connective action" [1]. The patterns witnessed in the \#TUBill debate arguably evidence collective more than connective action due to the primacy of trade unions in the networks and promotion of content intended to encourage citizen action, such as signing petitions. A network of connective action, by contrast, displays less dominance of established organizations. With that said, protest against an issue such as the Trade Union Bill is highly likely to be organized by the unions themselves whereas other labour and employment issues may draw in a wider network of actors. Our on-going analysis of the daily activity of trade union accounts will aid our understanding in this respect of how online trade unionism may be characterized as collective or connective. It is also with this in mind that the next stage of our research aims to collect Twitter data in real time around emergent, contentious topics to uncover the extent and nature of trade union involvement, as well as the constitution of social networks engaging with these issues.

Methodologically, too, there are clear indications that by employing the complementary strategies of descriptive analysis using Twitonomy and social network analysis using NodeXL, we are able to understand the ways in which UK trade unions, individually and collectively, use Twitter. To return to the question of the influence that unions generate through their Twitter activity, while Twitonomy offers useful metrics that may indicate influence (follower/followed ratios, reach of tweets, retweet counts and percentages for example), a promising line of enquiry to follow is to elaborate these metrics to describe the strength of ties in the trade unions' networks - an approach that might be mirrored in any study of civil society organizations. Users liking union tweets, for instance, arguably represents a strong tie. Combining these with analysis of growth or change in networks over time, and offline "victories" for trade unions, would produce an in-depth picture of the role of Twitter for UK trade unions. 


\section{ACKNOWLEDGMENTS}

This research is supported by the Wales Institute of Social \& Economic Research, Data \& Methods Civil Society Research Centre funded by the ESRC.

\section{REFERENCES}

[1] Bennett, W. L. and Segerberg, A. 2012. The logic of connective action. Information, Communication \& Society. $15,5,739-768$

[2] Bohman, J. 2004. Expanding dialogue: The Internet, the Public sphere and prospects for transnational democracy. In Crossley, N. and Roberts, J. M. (eds.) After Habermas: New Perspectives on the Public Sphere. Oxford: Blackwell

[3] Bruns, A. and Stieglitz, S. 2013. Towards a more systematic twitter analysis: Metrics for tweeting activities. International Journal of Social Research Methodology 16, 2, 91-108

[4] Bryson, A., Gomez, R. and Willman, P. 2010. Online social networking and trade union membership: What the Facebook phenomenon truly means for labor organizers. Labor History. 51, 1, 41-53

[5] Carter, C., Clegg, S., Hogan, J. and Kornberger, M. 2003. The polyphonic spree: The case of the Liverpool dockers. Industrial Relations Journal. 34, 4, 290-304 DOI: 10.1111/1468-2338.00276

[6] Castells, M. 2000. The Rise of the Network Society. $2^{\text {nd }}$ ed. Malden: Blackwell

[7] Castells, M. 2008. The new public sphere: Global civil society, communication networks, and global governance. The ANNALS of the AAPSS 616, 1

[8] Charman-Anderson, S. 2010. Making the Connection: The Use of Social Technologies in Civil Society. Carnegie UK Trust, Dunfermline

[9] Clauset, A., Newman, M. E. J. and Moore, C. 2004. Finding community structure in very large networks. Phys.Rev.E 70, 6

[10] Diamond, W. J. and Freeman, R. B. 2002. Will unionism prosper in cyberspace? The promise of the internet for employee organization. British Journal of Industrial Relations, 40, 3, 569-596

[11] Diginomy Pty Ltd. 2017. Twitonomy [software]. [Online] www.twitonomy.com

[12] Gleason, B. 2013. \#Occupy Wall Street: Exploring informal learning about a social movement on Twitter. American Behavioural Scientist. 57, 7, 966-982

[13] Greene, A-M. and Kirton, G. 2003. Possibilities for remote participation in trade unions: Mobilising women activists. Industrial Relations Journal. 34, 4, 319-333

[14] Greene, A-M., Hogan, J. and Grieco, M. 2003. Ecollectivism and distributed discourse: new opportunities for trade union democracy. Industrial Relations Journal. 34, 4, 282-289. DOI: 10.1111/1468-2338.00275

[15] Hodder, A. and Houghton, D. 2015. Union use of social media: a study of the university and college union on Twitter. New Technology, Work and Employment. 30, 3, 173 189

[16] Hogan, J., Nolan, P. and Grieco, M. 2010. Unions, technologies of coordination, and the changing contours of globally distributed power. Labor History, 51, 1, 29-40
[17] Kerr, A. and Waddington, J. 2013. E-communications: an aspect of union renewal or merely doing things electronically? British Journal of Industrial Relations. 52, 4, 658-681. DOI: 10.1111/bjir.12010

[18] LabourStart. 2013. 2013 Annual Survey of Trade Union Use of the Net [Online] http://www.labourstart.org/2013SurveyResults.pdf

[19] Lévesque, C. and Murray, G. 2010. Understanding union power: resources and capabilities for renewing union capacity. Transfer: European Review of Labour and Research. 16, 3, 333-350

[20] Loader, B. D. and Mercea, D. 2012. Social Media and Democracy: Innovations in Participatory Politics. London: Routledge

[21] Masters, M.F., Gibney, R., Zagencyk, T.J. and Shevchuk, I. 2010. Union members' usage of IT. Industrial Relations. 49, $1,83-90$

[22] Panagiotopolous, P. 2012. Towards unions 2.0: Rethinking the audience of social media engagement. New Technology, Work and Employment. 27, 3, 178-192

[23] Panagiotopolous, P. and Barnett, J. 2015. Social media in union communications: An international study with UNI Global Union affiliates. British Journal of Industrial Relations. 53, 3, 508-532. DOI: 10.1111/bjir.12060

[24] Shirky, C. 2011. The political power of social media: technology, the public sphere and political change. Foreign Affairs (Jan/Feb 2011)

[25] Social Media Research Foundation. 2014. NodeXL Pro [software]. [Online] http://www.smrfoundation.org/nodexl

[26] Stevens, C. D. and Greer, C. R. 2005. E-voice, the internet, and life within unions: Riding the learning curve. WorkingUSA. 8, 4, 439-455

[27] Tierney, T. 2013. The Public Space of Social Media: Connected Cultures of the Network Society. London: Routledge

[28] Tinati, R., Halford, S., Carr, L. and Pope, C. 2014. Big data: Methodological challenges and approaches for sociological analysis. Sociology, 48, 4, 663-681

[29] Wellman, B. and Hogan, B. 2004. The immanent Internet. In McKay, J. ed. Netting Citizens: Exploring Citizenship in a Digital Age. Edinburgh: St Andrew Press

[30] Williams, M. L., Burnap, P., Sloan, L. and Jessop C. 2016. DFID Practice Note: Using Social Media Data in International Development Research, Monitoring and Evaluation. London: NatCen 